\title{
Developmental dysplasia of the hip - angle trends after operation in different age groups
}

\author{
Sonja Milasinovic ${ }^{1}$, Radivoj Brdar ${ }^{2}$, Ivana Petronic ${ }^{3}$, Dejan Nikolic ${ }^{3}$, Dragana Cirovic $^{3}$
}

1Institute for Children's Disease, Clinical Centre of Montenegro, Podgorica, Montenegro 2Paediatric Orthopaedics, University Children's Hospital, Belgrade, Serbia

3Physical and Rehabilitation Medicine Department, University Children's Hospital, Belgrade, Serbia

Submitted: 28 October 2009

Accepted: 25 December 2009

Arch Med Sci 2010; 6, 5: 800-805

DOI: 10.5114/aoms.2010.17098

Copyright $\odot 2010$ Termedia \& Banach

\section{Abstract}

Introduction: The aim of our study was to evaluate changes in collodiaphyseal, Hilgenreiner and Wiberg's centre-edge angle values in different age groups of children before and after surgical correction of developmental dysplasia of the hip. Material and methods: We evaluated 78 children with developmental hip dysplasia treated at University Children's Hospital in Belgrade during a 10-year period. Three age groups were analysed: the first group younger than 24 months of life, the second group between 25 and 48 months, and the third group older than 48 months of life. Three angles were evaluated separately before and after surgical correction: collodiaphyseal angle, Hilgenreiner angle and Wiberg's centreedge angle.

Results: We found a highly statistically significant difference $(p<0.001)$ before and after the operation for collodiaphyseal and Hilgenreiner angle in the first and second age group, while there was a statistically significant difference $(p<0.05)$ in the third age group. Regarding Wiberg's centre-edge angle, there was a highly statistically significant difference $(p<0.001)$ in all age groups. One way ANOVA revealed a highly statistically significant difference $(p<0.001)$ for collodiaphyseal and Hilgenreiner angle in age groups before the operation, while after surgery such a trend remained for Hilgenreiner angle. Regarding collodiaphyseal and Wiberg's centre-edge angle in the period after correction, there was no statistical difference $(p>0.05)$ between age groups of the participants.

Conclusions: Our findings demonstrate that age of participants is in correlation with correction of values for collodiaphyseal angle, Hilgenreiner angle and Wiberg's centre-edge angle in surgically treated children diagnosed with developmental dysplasia of the hip.

Key words: developmental hip dysplasia, collodiaphyseal angle, Hilgenreiner angle, Wiberg's centre-edge angle.

\section{Introduction}

Developmental dysplasia of the hip (DDH) is one of the most frequent congenital defects of the locomotor apparatus, with an incidence of $1-3$ in 1000 newborns [1, 2].

The prognostic value for different angles measured in patients with DDH is still controversial [3]. Wiberg was first to describe the centre-edge angle. Values for this angle greater than 25 degrees are considered to be
Corresponding author: Dejan Nikolic MD, MSc Physical and Rehabilitation Medicine Department University Children's Hospital

Nikole Stefanovica 3 11000 Belgrade, Serbia Phone: +381638133345

E-mail:

denikol27@yahoo.com 
normal, while those less than 20 degrees were associated with acetabular dysplasia [4]. It has been observed in several studies that Wiberg's angle is of prognostic value as an early predictor of final outcome regarding hip development 5 years after reduction [3, 5]. Hilgenreiner angle (acetabular index) is of predictive value for Severin grade in order to assess the necessity for total hip replacement [6]. Further, it is shown to be a reliable parameter for the radiological diagnosis of DDH in children [7].

However, there are still insufficient data regarding the trend of collodiaphyseal angle followup in children with DDH before and after the operation in different age groups.

Beside conservative treatment with a Pavlik harness in infants, the surgical approach is useful in treatment of those children who failed conservative therapy and for older ones [8-10].

Therefore the aim of our study was to evaluate changes in collodiaphyseal, Hilgenreiner and Wiberg's centre-edge angle values in different age groups of children before and after surgical correction of $\mathrm{DDH}$.

\section{Material and methods}

\section{Study group}

We evaluated 78 children who were diagnosed with DDH and surgically treated in the Orthopaedic Department at the University Children's Hospital in Belgrade during a 10-year period from 1998 to 2008. The study design is retrospective. All children were completely assessed clinically by a paediatric surgeon, physiatrist and radiologist with the appropriate diagnostic evaluation in order to confirm the diagnosis.

Salter's innominate osteotomy with abrevational femoral derotation was done in evaluated patients.

There are studies suggesting measures in order to prevent possible complications and mortality in the post-surgical period [11]. Since possible infection in the period after surgical reduction can influence recovery and overall outcome, all children were carefully evaluated both by an orthopaedic surgeon and paediatricians.

According to age structure all patients were divided into 3 groups: the first group younger than 24 months of life, the second group between 24 and 48 months of life, and the third group older than 48 months of life. Classification of age groups was done according to the age when surgery was performed. For young patients we performed ultrasonography since it is the method of choice due to the ability of visualization of femoral head anatomical determinants and acetabulum. Older children were assessed by plane radiography, even though it is suggested that ultrasonography can be an alternative imaging method [12]. Femoro-gluteal furrow asymmetry was present in all patients, while Ortolani and Barlow signs were not observed because there were children older than 12 months of life. Since some members of the evaluated group were infants, they were initially treated with nonsurgical methods. As the reference duration for the Pavlik harness we used the period of 2 weeks for the purpose of obtaining stable reduction [10]. Those that failed to achieve such a result were candidates for a surgical procedure. In order to exclude possible errors that can arise in evaluation of angles before and after surgery from the group of infants who failed to achieve stable reduction we included only those who had a difference in angle less than one degree comparing values before introduction of the Pavlik harness and the operation. Three angles were evaluated separately: collodiaphyseal angle, Hilgenreiner angle and Wiberg's centre-edge angle. Values for these angles were taken before the operation and after the operation.

For the purpose of general assessment after surgical reduction we used leg length discrepancy, Trendelenburg's sign and walking symmetry. Trendelenburg's sign was classified in two categories, negative and positive, while walking symmetry was classified as present or absent.

\section{Statistical analysis}

Values for all angles and leg length discrepancy were expressed as mean with standard deviation (SD) as well with minimal and maximal values. Comparison of mean values for each angle before and after surgical intervention in every age group was done by Student's t test. To compare values of angles separately before and after surgery and leg length discrepancies after surgery in age groups we used one way ANOVA test. For comparison between presence and absence for Trendelenburg's sign as well for walking symmetry between two different age groups $\chi^{2}$ test was used.

\section{Results}

Our study evaluated 78 children who were diagnosed with DDH and treated at University Children's Hospital in Belgrade during a 10-year period. In the group of children younger than 24 months we had 25 (32.05\%) patients, in the group between 25 and 48 months we had $34(43.59 \%)$ patients, and in the third age group we had 19 (24.36\%) patients.

In Table I we present changes in collodiaphyseal angle values after surgical treatment of DDH in different age groups. Our results show that there is a highly statistically significant difference $(p<0.001)$ for collodiaphyseal angle correction after 
Table I. Collodiaphyseal angle values before and after operation

\begin{tabular}{|lccccc|}
\hline \multirow{2}{*}{ Age groups } & Surgery status & \multicolumn{4}{c|}{ Collodiaphyseal angle } \\
\cline { 2 - 5 } & & Mean \pm SD & Minimal value & Maximal value & \multirow{2}{*}{ t values } \\
\cline { 2 - 5 } First group & Before & $158.37 \pm 11.28$ & 143.00 & 180.00 & \multirow{2}{*}{$9.20^{* *}$} \\
\cline { 2 - 5 } & Post & $136.14 \pm 4.31$ & 125.00 & 145.00 & \\
\hline Second group & Before & $145.07 \pm 8.29$ & 128.00 & 161.00 & \multirow{2}{*}{$4.43^{* *}$} \\
\cline { 2 - 5 } & Post & $136.84 \pm 6.98$ & 118.00 & 150.00 & \\
\hline Third group & Before & $145.12 \pm 10.17$ & 134.00 & 160.00 & \multirow{2}{*}{$2.47^{*}$} \\
\cline { 2 - 5 } & Post & $137.06 \pm 9.93$ & 120.00 & 147.00 & \\
\hline
\end{tabular}

${ }^{*} p<0.05 ;{ }^{* *} p<0.001$

the surgical procedure in the first and second age group, while there is a significant statistical difference $(p<0.05)$ for those older than 48 months of life.

One way ANOVA for collodiaphyseal angle values in age groups before the operation showed a high statistical significance $(F=15.28 ; p<0.01)$, while these values after the operation were not statistically different $(F=0.10 ; p>0.05)$.

In Table II we present changes in Hilgenreiner angle values after surgical treatment of DDH in different age groups. Our results show a highly statistically significant difference $(p<0.001)$ for Hilgenreiner angle correction after the surgical procedure in the first and second age group, while for patients with DDH aged above 48 months at the time of the operation there is a significant statistical difference $(p<0.05)$.

One way ANOVA for Hilgenreiner angle values in age groups before the operation showed high statistical significance $(F=15.99 ; p<0.001)$. The same level of statistical significance for the abovementioned angle remained after the operation $(F=22.62 ; p<0.001)$.

In Table III we present changes in Wiberg's centre-edge angle values after surgical treatment of patients with DDH in different age groups. Our results show that there is a highly statistically significant difference $(p<0.001)$ for Wiberg's centre-

Table II. Hilgenreiner angle values before and after operation

\begin{tabular}{|lccccc|}
\hline \multirow{2}{*}{ Age groups } & Surgery status & \multicolumn{3}{c|}{ Hilgenreiner angle } \\
\cline { 2 - 5 } & & Mean \pm SD & Minimal value & Maximal value & $t$ values \\
\hline First group & Before & $35.31 \pm 6.17$ & 22.00 & 46.00 \\
\cline { 2 - 5 } & Post & $15.96 \pm 2.48$ & 11.00 & 20.00 \\
\hline Second group & Before & $39.02 \pm 6.14$ & 25.00 & 54.00 \\
\cline { 2 - 5 } & Post & $19.23 \pm 3.67$ & 14.00 & 27.00 \\
\hline
\end{tabular}

${ }^{*} p<0.05 ;{ }^{* *} p<0.001$

Table III. Wiberg's centre-edge angle before and after operation

\begin{tabular}{|c|c|c|c|c|c|}
\hline \multirow[t]{2}{*}{ Age groups } & \multirow[t]{2}{*}{ Surgery status } & \multicolumn{3}{|c|}{ Wiberg's centre-edge angle } & \multirow[b]{2}{*}{$t$ values } \\
\hline & & Mean \pm SD & Minimal value & Maximal value & \\
\hline \multirow[t]{2}{*}{ First group } & Before & $8.21 \pm 6.87$ & -5.00 & 22.00 & \multirow[t]{2}{*}{$15.45^{*}$} \\
\hline & Post & $34.69 \pm 5.12$ & 25.00 & 46.00 & \\
\hline \multirow[t]{2}{*}{ Second group } & Before & $-3.82 \pm 15.93$ & -40.00 & 19.00 & \multirow[t]{2}{*}{$11.45^{*}$} \\
\hline & Post & $32.27 \pm 9.18$ & 12.00 & 47.00 & \\
\hline \multirow[t]{2}{*}{ Third group } & Before & $9.32 \pm 6.11$ & 0.00 & 21.00 & \multirow[t]{2}{*}{$9.62^{*}$} \\
\hline & Post & $31.83 \pm 8.17$ & 20.00 & 52.00 & \\
\hline
\end{tabular}

${ }^{*} p<0.001$ 
edge angle correction after the surgical procedure in the first, second and third age group.

One way ANOVA for Wiberg's centre-edge angle values in age groups before the operation showed statistical significance $(F=10.92 ; p<0.001)$, while these values after surgical correction were not statistically different $(F=0.91 ; p>0.05)$.

In Table IV assessment of surgical reduction in patients with DDH according to age groups is presented. One way ANOVA for leg length discrepancies in different age groups after the operation showed statistical significance $(F=28.46$; $p<0.001)$.

Trendelenburg's sign and walking symmetry are analysed in Table $\mathrm{V}$. Our results show that there is a significant absence of Trendelenburg's sign in every age group ( $p<0.001)$, particularly in the first and second age group, where it was noticed that there is absolute absence, while walking symmetry was predominantly observed for all age groups as well $(p<0.001)$.

\section{Discussion}

Developmental dysplasia of the hip is reported to be among the most common congenital skeletal diseases [13]. Some authors point out that among all diagnosed congenital defects, DDH has a frequency of about 75\% [14]. While in most cases DDH resolves spontaneously in the first several months after birth, persistent form can lead to gait abnormalities and in some cases to degenerative arthritis [15-17]. If acetabular dysplasia after the treatment of DDH appears and is left untreated, it could lead to early degenerative joint disease [6].

Table IV. Leg length discrepancy in different age groups after surgical reduction

\begin{tabular}{|lccc|}
\hline \multirow{2}{*}{ Age groups } & \multicolumn{3}{c|}{ Leg length discrepancy $[\mathrm{cm}]$} \\
\cline { 2 - 4 } & Mean \pm SD & $\begin{array}{c}\text { Minimal } \\
\text { value }\end{array}$ & $\begin{array}{c}\text { Maximal } \\
\text { value }\end{array}$ \\
\hline First group & $0.65 \pm 0.23$ & 0.50 & 1.00 \\
\hline Second group & $1.28 \pm 0.46$ & 1.00 & 2.00 \\
\hline Third group & $1.52 \pm 0.48$ & 1.00 & 2.00 \\
\hline
\end{tabular}

Table V. Distribution of Trendelenburgs sign and walking symmetry in different age groups

\begin{tabular}{|lcccc|}
\hline \multirow{2}{*}{ Age groups } & \multicolumn{3}{l}{ Trendelenburg's sign } & Walking symmetry \\
\cline { 2 - 5 } & Negative & Positive & Present & Absent \\
\hline $\begin{array}{l}\text { First group, } \\
n(\%)\end{array}$ & $25(100)$ & $0^{*}(0)$ & $25(100)$ & $0^{*}(0)$ \\
\hline $\begin{array}{l}\text { Second group, } \\
n(\%)\end{array}$ & & & & \\
\hline $\begin{array}{l}\text { Third group, } \\
n(\%)\end{array}$ & $17(89.47)$ & $2^{*}(10.53)$ & $17(89.47)$ & $2^{*}(10.53)$ \\
\hline${ }^{*} p<0.00$ & & & \\
\hline
\end{tabular}

There are studies stressing that almost $60 \%$ of newborns with DDH have no identifiable risk factors [18]. However, some determinants can be predictors for such a state. These determinants include: female gender, breech presentation at delivery, positive family history, and others [19]. Further, Cady and colleagues in their study point out that approximately $15 \%$ of children with DDH at birth are undiagnosed [20]. Therefore it is of great importance to educate physicians, particularly radiologists and paediatric surgeons, to timely recognize such a condition in order to prevent possible complications. Early detection in infancy with prompt treatment with a Pavlik harness is associated with high success rates, while for those older than 13 weeks treatment can be prolonged [21].

For most children younger than 18 months severe late dysplasia could be identified by the trend of the Hilgenreiner angle and for all children at five years by measurement of Wiberg's centreedge angle [22].

In our study we demonstrated that trends of collodiaphyseal angle and Hilgenreiner angle in children with DDH before and after surgery in different age groups correlate more closely with the age of the child than Wiberg's centre-edge angle. Justification for this observation for the first two above-mentioned angles is in the statistical analysis, where we found a highly significant reduction $(p<0.001)$ of angle values in the first and second age groups, while for the third it was significantly reduced $(p<0.05)$. These findings are in line with other authors regarding the influence of age as a predicting factor for the outcome of $\mathrm{DDH}$ reduction due to better capacity for remodelling [23, 24].

This observation indicates that the correction of collodiaphyseal angle and Hilgenreiner angle is more effective in younger children, while there is the same efficacy for correction of Wiberg's centreedge angle in all evaluated age groups.

It can be observed that the interval between minimal and maximal values for collodiaphyseal angle before surgical correction is shrinking as children are older for 5 degrees in every age group. In the period after correction such a decline is not observed, with the widest discrepancy between minimal and maximal values in the second age group of 30 degrees.

Regarding the interval for Hilgenreiner angle values, before surgical correction the widest interval between minimal and maximal values was in the second age group (27 degrees), while in the period after the operation such an interval shows an increase as children are older from 9 degrees for children aged less than 24 months to 14 degrees for those older than 48 months. Our findings show a shorter range of interval in evaluated patients after 
surgical reduction in comparison with other studies [25] using Salter's technique, while mean angle values were in line with other authors' results [25].

We did not find any correlation regarding trends in interval values between minimal and maximal values for Wiberg's centre-edge angle regarding age of participants in our study. Our results showed that the greatest correction was achieved in the second age group of patients with $\mathrm{DDH}$ regarding the above-mentioned angle. Since angle values less than 15 degrees [26] are considered for surgical reduction, performed Salter's innominate osteotomy gains post-surgical trends of angles regarding Wiberg's centre-edge angle above 25 degrees [27] in all age groups, suggesting its beneficial role in correction of DDH. Our approaches with Salter's technique give postsurgical mean angle values that are in line with other studies, especially in patients from the first two age groups [25].

Results interpreted by one way ANOVA showed that there was a statistical change for collodiaphyseal angle and Wiberg's centre-edge angle before and after surgical correction, indicating more uniform results in the period after the operation, while for Hilgenreiner angle we did not observe such statistical change. In fact, statistical significance remained at the same level $(p<0.001)$.

Regarding leg length discrepancy, presence of Trendelenburg's sign and walking symmetry, the results show that Salter's innominate osteotomy is effective in management of patients with DDH. The effectiveness of this technique was previously described as good in patients below 10 years of age in numerous studies [28, 29].

Our results showed that correction of collodiaphyseal and Wiberg's centre-edge angle with surgical reduction in children with DDH is more efficient than surgical reduction of Hilgenreiner angle in different age groups. Younger children obtained better results regarding angle reduction. Furthermore, surgical correction was shown to be beneficial in all age groups regarding walking symmetry, while it is more efficient in younger children regarding leg length discrepancy.

These findings stress the importance of early diagnostics and prompt and adequate treatment of children with DDH.

\section{References}

1. Dezateux C, Rosendahl K. Developmental dysplasia of the hip. Lancet 2007; 369: 1541-52.

2. Tredwell SJ. Neonatal screening for hip joint instability. Its clinical and economic relevance. Clin Orthop Relat Res 1992; 281: 63-8.

3. Tudor A, Dalen L, Dugan R, Tomislav P, Ratko S. Prognostic value of refined Wiberg's angle in hip development. Coll Antropol 2005; 29: 267-70.
4. Fredensborg N. The CE angle of normal hips. Acta Orthop Scand 1976; 47: 403-5.

5. Kitoh H, Kitakoji T, Katoh M, Ishiguro N. Prediction of acetabular development after closed reduction by overhead traction in developmental dysplasia of the hip. J Orthop Sci 2006; 11: 473-7.

6. Albinana J, Dolan LA, Spratt KF, Morcuende J, Meyer MD, Weinstein SL. Acetabular dysplasia after treatment for developmental dysplasia of the hip. Implications for secondary procedures. J Bone Joint Surg Br 2004; 86: 876-86.

7. Neidel J, Tönnis D. Percentile graphs in the documentation of acetabular angle in children with hip dysplasia. A tool in the diagnosis and quality control of its treatment. Z Orthop Ihre Grenzgeb 1994; 132: 512-5.

8. López-Carreño E, Carillo H, Gutiérrez M. Dega versus Salter osteotomy for the treatment of developmental dysplasia of the hip. J Pediatr Orthop B 2008; 17: 213-21.

9. El-Sayed MM. Single-stage open reduction, Salter innominate osteotomy, and proximal femoral osteotomy for the management of developmental dysplasia of the hip in children between the ages of 2 and 4 years. J Pediatr Orthop B 2009; 18: 188-96.

10. Guille JT, Pizzutillo PD, MacEwen GD. Development dysplasia of the hip from birth to six months. J Am Acad Orthop Surg 2000; 8: 232-42.

11. Piechota M, Banach M, Jacoń A, Rysz J. How can we decrease mortality in surgery units? Arch Med Sci 2007; 3: 367-75.

12. Ozçelik A, Akçar N, Inan U, Omeroğlu H. Assessment of the use of hip ultrasonography by Graf's method between 1 and 6 years of age. J Pediatr Orthop B 2005; 14: 97-100.

13. Ihme N, Schmidt-Rohlfing B, Lorani A, Niethard FU. Nonsurgical treatment of congenital dysplasia and dislocation of the hip. Orthopade 2003; 32: 133-8.

14. Kokavec M, Bialik V. Developmental dysplasia of the hip. Prevention and real incidence. Bratisl Lek Listy 2007; 108: 251-4.

15. Boeree NR, Clarke NMP. Ultrasound imaging and secondary screening for congenital dislocation of the hip. J Bone Joint Surg Br 1994; 76: 525-33.

16. Hansson G, Jacobsen S. Ultrasonography screening for developmental dysplasia of the hip joint. Acta Paediatr 1997; 86: 913-5.

17. Dwyer NS. Congenital dislocation of the hip: To screen or not to screen? Arch Dis Child 1987; 62: 635-7.

18. Patel H. Canadian Task Force on Preventive Health Care. Preventive health care, 2001 update: screening and management of developmental dysplasia of the hip in newborns. CMAJ 2001; 164: 1669-77.

19. Stein-Zamir C, Volovik I, Rishpon S, Sabi R. Developmental dysplasia of the hip: risk markers, clinical screening and outcome. Pediatr Int 2008; 50: 341-5.

20. Cady RB. Developmental dysplasia of the hip: definition, recognition, and prevention of late sequelae. Pediatr Ann 2006; 35: 92-101.

21. Eidelman M, Katzman A, Freiman S, Peled E, Bialik V. Treatment of true developmental dysplasia of the hip using Pavlik's method. J Pediatr Orthop B 2003; 12: 253-8.

22. Cashman JP, Round J, Taylor G, Clarke NM. The natural history of developmental dysplasia of the hip after early supervised treatment in the Pavlik harness. A prospective, longitudinal follow-up. J Bone Joint Surg Br 2002; 84: 418-25.

23. Chen IH, Kuo KN, Lubicky JP. Prognosticating factors in acetabular development following reduction of developmental dysplasia of the hip. J Pediatr Orthop 1994; 14: 3-8. 
24. Kitoh H, Kitakoji T, Katoh M, Ishiguro N. Prediction of acetabular development after closed reduction by overhead traction in developmental dysplasia of the hip. J Orthop Sci 2006; 11: 473-7.

25. Tukenmez M, Tezeren G. Salter innominate osteotomy for treatment of developmental dysplasia of the hip. J Orthop Surg (Hong Kong) 2007; 15: 286-90.

26. Grissom L, Harcke HT, Thacker M. Imaging in the surgical management of developmental dislocation of the hip. Clin Orthop Relat Res 2008; 466: 791-801.

27. Delaunay S, Dussault RG, Kaplan PA, Alford BA. Radiographic measurements of dysplastic adult hips. Skeletal Radiol 1997; 26: 75-81.

28. Ito H, Ooura H, Kobayashi M, Matsuno T. Middle-term results of Salter innominate osteotomy. Clin Orthop Relat Res 2001; 387: 156-64.

29. Vengust, R, Antolic V, Srakar F. Salter osteotomy for treatment of acetabular dysplasia in developmental dysplasia of the hip in patients under 10 years. J Pediatr Orthop B 2001; 10: 30-6. 